\title{
Efektifitas Edukasi TB Paru melalui Booklet Berbahasa Tetun Terhadap Pengetahuan dan Sikap Keluarga Dalam Pencegahan Penularan TB Paru di Centru Saude Comoro, Dili, Timor Leste.
}

\author{
Maria Goreti Owa ${ }^{1}$, Erna Rochmawati ${ }^{2}$ \\ ${ }^{1}$ Fakultas Ilmu Kesehatan, Program Studi Ilmu Keperawatan, Universitas Oriental Timor \\ Lorosa'e. \\ ${ }^{2}$ Magister Keperawatan, Program Pasca Sarjana, Universitas Muhammadiyah Yogyakarta, \\ ${ }^{1}$ mariagoretiowa@yahoo.com*,2erna.rochmawati@umy.ac.id. \\ *Corresponding author
}

\section{INFORMASI ARTIKEL \\ Sejarah Artikel \\ Received: 10-04-2020 \\ Revised : 17-04-2020 \\ Accepted: 18-04-2020}

Kata Kunci:

Tuberculosis

Kepatuhan, pengetahuan

\section{ABSTRAK}

Tuberkulosis atau TB Paru adalah penyakit menular yang disebabkan oleh bakteri Mycobacterium Tuberculosis atau biasa disebut kuman TB. Sebagian besar dari bakteri ini sering menyerang sistem pernapasan yaitu paru-paru, tetapi bakteri ini juga dapat menyerang sistem organ tubuh lainnya. Waktu pengobatan tuberkulosis yang cukup lama mengakibatkan beberapa pasien merasa bosan, karena pada umumnya pengetahuan keluarga pasien sangat minim sehingga sikap keluarga kurang maksimal dalam merawat penderita paru, TB. Media edukasi melalui Booklet berbahasa Tetun merupakan suatu desain yang menarik karena didalam booklet berisi tentang kalimat dan gambar yang mudah dipahami dan menggunakan bahasa lokal yaitu bahasa Tetun, sehingga dapat memotivasi pasien maupun keluarga untuk membaca agar dapat meningkatkan pengetahuan serta perubahan sikap baik keluarga maupun pasien dalam memelihara kesehatan serta meningkatkan kualitas hidup sehat. Tujuan: Menganalisis efektifitas edukasi TB melalui booklet berbahasa Tetun terhadap pengetahuan dan sikap keluarga dalam Pencegahan penularan TB. Metode: Menggunakan desain studi one group pre-post test design. Sampel: 63 orang. Instrumen penelitian: Kuesioner tentang pengetahuan dan sikap keluarga dalam pencegahan TB Paru.Hasil: Pengetahuan keluarga terjadi peningkatan sebelum diberikan booklet pada tingkatan pengetahuan keluarga baik dengan skor 92,1\% menjadi $100 \%$ setelah diberikan booklet. Sikap keluarga juga terjadi peningkatan sebelum diberikan booklet pada tingkatan sikap keluarga yang cukup dengan skor 69,8\% menjadi 76,2\% setelah diberikan booklet. Uji Wilcoxon Signed Test menunjukkan adanya peningkatan signifikan pada pengetahuan maupun sikap keluarga dalam pencegahan penularan TB paru. Kesimpulan: Edukasi TB melalui media booklet berbahasa Tetun efektif dalam meningkatkan pengetahuan serta perubahan sikap keluarga dalam pencegahan penularan $\mathrm{TB}$, dilihat pada peningkatan nilai pengetahuan keluarga menjadi seluruhnya berpengetahuan baik dan juga sikap keluarga ada peningkatan nilai pada tingkatan sikap cukup

\section{ABSTRACT}

Keywords:

Pulmonary tuberculosis, compliance, knowledge
Introduction: Tuberculosis (TB) is one of the public health problems that cannot be overcome. The problem is caused by several factors, one of which is the non-compliance of patients with treatment. In Indonesia, the incidence of TB cases is 842,000 per year and notification of TB cases is 569,899 cases, so there are still around 32\% of the cases that have not been verified either unreached, undetected or not reported. From this incident rate the TB burden is calculated in each province and district / city, (Indonesia, 2019). Purpose: Identify factors related to adherence to the treatment of pulmonary $T B$ patients in the working area of Garuda Bandung Puskesmas. Method: This is an analytic case study with a case control design. The sample of this study was 43 pulmonary TB patients taken in total who failed and were removed from treatment in 2017. The research instrument used a questionnaire. Data 
analysis using chi square. Results: The most dominant factors affecting adherence to treatment among pulmonary TB patients were Gender $P$ value (0.014) and occupational Pvalue (0.025) where $p<0.05$ while factors not related to medication adherence were age, knowledge, education, and family income, $p>0.05$. Conclusion: Gender and occupation have a significant relationship to tuberculosis treatment adherence, while age, knowledge and family income have no significant relationship to tuberculosis patient adherence.

\section{PENDAHULUAN}

Tuberkulosis Paru merupakan suatu penyakit yang disebabkan oleh bakteri Mycobacterium Tuberkulosis atau biasa disebut kuman TB, kuman TB sering menyerang sistem pernapasan yaitu paru-paru dan juga dapat menyerang diberbagai organ tubuh lainnya seperti meningen, ginjal, tulang, nodus limfe dan lain sebagainya (Smeltzer \& Bare, 2015). Diberbagai negara berkembang di dunia hasil rekapan data tahun 2015 hampir 1015\% dari angka kesakitan berbagai penyakit pada anak dibawah usia 6 tahun sebagian besar adalah penyakit Tuberkulosis Paru. TB paru merupakan penyakit yang menjadi perhatian global, sehingga dengan berbagai upaya untuk mengendalikan angka kejadian dan angka kematian TB paru, walaupun sudah melakukan pengendalian TB Paru akan tetapi penyakit ini masih menyerang 9,6 juta penduduk dan mengakibatkan kematian sebanyak 1,2 juta penduduk.

Penyakit tuberkulosis secara umum mulai terinfeksi pada tahun 2016 terdapat 104 juta kasus (CI 8,8 juta-12 juta) setara dengan 120 juta kasus per 100.000 penduduk. Penyakit tuberkulosis di wilayah Indonesia merupakan penyakit yang mendapatkan peringkat ke-2 di tingkat dunia terbanyak setelah India dan China, Filipina, Pakistan, Nigeria dan Afrika Selatan. Data penyakit Tuberkulosis di Indonesia pada tahun 2016 yaitu 1.020.000 penderita. Insiden dan prevalensi tuberkulosis di masyarakat sendiri masih cukup besar dan data kematian tahun 2016 terdapat 274 kasus (WHO, 2017).

Menurut WHO (2018) bahwa kasus TB Indonesia terbesar ketiga dunia dari 10 Negara. Adapun 10 negara yang mempunyai kasus TB banyak yaitu India (2,7 juta), Tiongkok (889.000), Indonesia (581.000), Pakistan (525.000), Nigeria (418.000), Bangladesh (364.000), Afrika Selatan (322.000), Republik Kongo (262.000) dan Myanmar (191.000). Sedangkan menurut data MDS (Ministerio Da Saude) bahwa data penyakit tuberkulosis di Negara Timor Leste mulai bulan Januari sampai Desember 2014 adalah me'ar tasak positivu ada 1.923 (51\%), me'ar tasak negativu 1.342 (35\%), extra pulmonari 519 (14\%), pada tahun 2015 me'ar tasak positivu 1.923 (51\%), me'ar tasak negativu 1.336 (35\%), extra pulmonari 519 (14\%), sedangkan pada tahun 2016 me'ar tasak positivu 1.908 (55\%), me'ar tasak negativu 1.157 (34\%) dan extra pulmonari 386 (11\%). Menurut data dari SSM (Servisu Saude Municipiu Dili bahwa angka kejadian TB paru untuk distrik Dili tahun 2014 sampai 2017 adalah 915 pasien. Data di Centru Saude Comoro mulai bulan Januari sampai dengan bulan Juli 2018 terdapat 167 pasien dengan diagnosa TB Paru sedangkan pada tahun 2018 meningkat menjadi 178 pasien TB merupakan penyakit yang sangat berbahaya dengan penularan yang cepat melalui udara dari dahak, batuk dan bersin penderita TB yang bisa membahayakan bagi siapa saja yang tertular bakteri Mycobacterium Tuberculosis (Somantri, 2007). Menurut Yohana (2017) Penularan kuman TB dipengaruhi oleh kurangnya kesadaran penderita, masyarakat maupun keluarga dalam hal pencegahan penularan TB Paru, karena peran serta masyarakat ataupun keluarga dalam merubah sikap dan perilaku mereka sangatlah penting. WHO pada tahun 1995 merekomendasikan strategi Directly observed treatment short-course (DOTS) sebagai strategi dalam pengendalian penyakit TB paru. Namun program penanggulangannya ini masih belum maksimal atau masih rendah, karena angka kejadian TB Paru yang terjadi dimasyarakat masih sangat tinggi (Adewale, Podder, \& Gumel, 2009).

Tuberkulosis atau TB Paru merupakan salah satu penyakit yang mempunyai masalah terbesar dalam kesehatan keluarga atau masyarakat di seluruh dunia sampai saat ini. Upaya untuk mengendalikan TB Paru yaitu dengan pengobatan secara Tuntas pada penderita 
TB. Pengobatan serta merubah sikap dan perilaku merupakan upaya yang paling efektif untuk mencegah penularan kuman TB pada keluarga maupun masyarakat. Cara pengendalian TB Paru dengan DOTS ada lima (5) kunci utama yaitu menemukan kasus melalui pemeriksaan dahak, pengobatan yang baik serta ada PMO bagi setiap pasien, ketersedian OAT dan pengelolaannya secara maksimal, selalu ada monitoring pada pasien, mencatat dan melaporkan hasil dari program dan pengobatan pasien.

Pencegahan penularan TB ini dilakukan untuk mencegah orang disekitar penderita baik keluarga maupun masyarakat agar tidak tertular kuman TB. Faktor yang sangat penting dalam pencegahan penularan $\mathrm{TB}$ di keluarga maupun di masyarakat adalah faktor pengetahuan, sikap, pendidikan serta perilaku seseorang dalam menanggulangi pencegahan penularan penyakit TB (Notoadmojo, 2010). Hasil penelitian suprayitno 2017 Pasien dengan tingkat pendidikan yang lebih tinggi akan memiliki efikasi diri dan perawatan diri yang lebih baik. Salim tahun 2010 mengatakan bahwa perilaku pasien dalam pencegahan penularan TB masih sangat rendah. Perilaku pencegahan TB pada masyarakat atau penderita adalah menutup mulut dan hidung dengan mengunakan tisu atau sapu tangan pada waktu bersin atau batuk, meludah atau mengeluarkan dahak di tempat yang sudah diberi desinfektan dalam wadah tertutup, ventilasi rumah yang baik agar sinar matahari bisa masuk, imunisasi BCG pada bayi, menjemur bantal dan kasur setiap seminggu dua kali, memisahkan barang yang digunakan penderita TB di cuci dengan sabun dan direndam menggunakan air panas (Mujahidin, 2013).

Berdasarkan penelitian media buku saku yang dilakukan Syahrini et al (2013) dengan hasil yang diperoleh yaitu terjadi perbedaan rata-rata pre dan post test pada nilai pengetahuan serta sikap PMO TB Paru dengan menggunakan media buku saku. Berdasarkan penelitian media buku saku bergambar dan berbahasa Madura yang dilakukan Maghfiroh et al (2017) membuktikan bahwa edukasi dengan menggunakan buku saku bergambar serta menggunakan bahasa Madura dapat meningkatkan pengetahuan pasien atau penderita maupun PMO (Pengawas Minum Obat) TB. Berdasarkan Studi kasus efektifitas dalam pemberian penyuluhan menggunakan media video dan stimulasi dalam meningkatkat pengetahuan pencegahan TB paru yang dilakukan Husnul Khatimah (2016) dengan hasil setelah penyuluhan pada kelompok yang menggunakan video maupun pada kelompok stimulasi tidak terdapat perbedaan yang bermakna dari kedua media ini dalam meningkatkan pengetahuan tentang pencegahan TB Paru.

Menurut Undang-Undang Dasar Republik Demokratik Timor Leste, pasal 57 tentang Kesehatan menyatakan bahwa setiap warga Negara berhak atas pelayanan kesehatan dan perawatan medis, Negara akan mengembangkan suatu sistem kesehatan nasional secara universal dan umum dan selama memungkinkan bebas biaya, pelayanan kesehatan nasional sejauh mungkin akan dikelolah secara desentralisasi dan partisipatif. Pengendalian TB Paru dengan menggunakan DOTS telah dilaksanakan sejak tahun 1997. Berdasarkan hasil wawancara dibulan Juli 2018 dengan kepala ruangan TB Paru di Centru Comoro mengatakan bahwa di Centru Saude (Puskesmas Kesehatan) Comoro sudah menggunakan strategi DOTS juga Pengawas minum obat untuk mencegah terjadinya peningkatan TB paru dan juga untuk menghindari pasien lupa minum obat dan jadwal kontrolnya, petugas selalu memberi informasi melalui penyuluhan atau memberitahukan secara langsung kepada penderita tentang penyakit TB Paru, kalau mengenai buku dan lain-lain belum pernah kami berikan kepada pasien dan keluarganya. Directly observed treatment short-course (DOTS) adalah salah satu program departemen kesehatan yang harus diimplementasikan di setiap pusat pelayanan kesehatan oleh petugas program $\mathrm{TB}$, bagi setiap petugas program TB berkewajiban mengawasi pasien tuberkulosis setiap kali minum obat. (Kementerian Kesehatan Timor Leste, 2008).

\section{METODE PENELITIAN}

Penelitian ini menggunakan Rancangan praeksperimental yaitu penelitian eksperimen dengan one group pre dan post test design Populasi dalam penelitian ini adalah keluarga pasien TB yang ada di Centru Saude Comoro sebanyak 167, Teknik 
sampling mengunakan teknik purposive sampling Instrumen yang digunakan yaitu kuesioner Untuk pengujian statistiknya pengukuran ordinal untuk pengetahuan dan sikap. Uji normalitas menggunakan uji Kolmogorov-Smirnov sedangkan untuk menganalisis data efektifitas edukasi mengunakan uji komparasi pada satu sampel berpasangan (dua pengamatan),

melalui booklet terhadap pengetahuan dan sikap keluarga dalam pencegahan penularan TB menggunakan uji Wilcoxon.

\section{HASIL PENELITIAN}

Tabel 1 Pengetahuan dan sikap Keluarga Sebelum dan Sesudah diberikan Booklet.

\begin{tabular}{ccccccccc}
\hline \multirow{2}{*}{ Kategori } & \multicolumn{4}{c}{ Pengetahuan } & \multicolumn{4}{c}{ Sikap } \\
\cline { 2 - 10 } & \multicolumn{3}{c}{ Pre Test } & \multicolumn{2}{c}{ Post Test } & Pre Test & \multicolumn{3}{c}{ Post Test } \\
\cline { 2 - 10 } & $\mathrm{N}$ & $(\%)$ & $\mathrm{N}$ & $(\%)$ & $\mathrm{N}$ & $(\%)$ & $\mathrm{N}$ & $(\%)$ \\
\hline Baik & 58 & 92,1 & 63 & 100 & 15 & 23,8 & 15 & 23,8 \\
\hline Cukup & 5 & 7,9 & - & - & 44 & 69,8 & 48 & 76,2 \\
\hline Kurang & - & - & - & - & 4 & 6,4 & - & - \\
\hline
\end{tabular}

Hasil dari analisis data yang dilihat pada Tabel 1 yaitu untuk melihat pengetahuan keluarga Pre Test atau sebelum diberikan booklet hampir seluruhnya berpengetahuan baik sebanyak 92,1\% sedangkan Post Test atau sesudah diberikan booklet seluruhnya meningkat menjadi 100\% berpengetahuan baik dan sikap keluarga Pre Test sebelum diberikan booklet sebagian besar memiliki sikap cukup sebanyak 69,8\% sedangkan hasil Post Test setelah diberikan booklet hampir seluruhnya 76,2\% mempunyai sikap cukup.

Tabel 2 Efektifitas Edukasi Tentang TB Melalui Booklet Berbahasa Tetun Terhadap Pengetahuan Dan Sikap Keluarga Dalam Mencegah Penularan TB

\begin{tabular}{llllllll}
\hline Variabel & $\begin{array}{l}\text { Mean } \\
\text { Rank }\end{array}$ & $\begin{array}{l}\text { Sum of } \\
\text { Rank }\end{array}$ & $\mathrm{Z}$ & Sig & $\begin{array}{l}\text { Positive } \\
\text { Ranks }\end{array}$ & $\begin{array}{l}\text { Negative } \\
\text { Ranks }\end{array}$ & Ties \\
\hline Pengetahuan & 3.00 & 15.00 & -2.236 & 0.025 & $0 \mathrm{~b}$ & $5 \mathrm{a}$ & $58 \mathrm{c}$ \\
Sikap & 2.50 & 10.00 & -2.000 & 0.046 & $0 \mathrm{e}$ & $4 \mathrm{~d}$ & $59 \mathrm{f}$ \\
\hline
\end{tabular}

Tabel 2 untuk analisis menggunakan uji Wilcoxon Signed Rank Test dari tabel dilihat bahwa hasil pre dan post test adalah kurang dari 0.05. Berdasarkan teori yang telah disampaikan sebelumnya, sehingga hasil yang diuji mendapatkan nilai signifikan untuk pengetahuan 0.025 dan sikap mendapat nilai yang signifikan 0.046 .

\section{PEMBAHASAN}

Hasil analisis yang didapat dari pre dan post test dengan menggunakan media yaitu booklet berbahasa Tetun terjadi peningkatan signifikan pada pengetahuan maupun sikap keluarga dalam pencegahan penularan TB, walaupun nilai sikap masih cukup tapi ada peningkatan nilai sikap sebelum dan sesudah diberikan booklet. Edukasi atau pendidikan adalah suatu upaya yang dilaksanakan oleh pendidik dalam memberi informasi kepada orang lain baik secara perorang ataupun secara berkelompok agar dapat merubah seseorang sesuai yang diharapkan oleh pemberi edukasi. Media Booklet adalahsuatu alat atau media cetak yang sangat menarik dan mudah untuk memelihara derajat kesehatannya baik secara fisik, mental dan juga sosialnya, sehingga menjadi manusia yang lebih menyampaikan informasi tentang kesehatan dalam bentuk tulisan dan gambar agar mudah dipahami oleh seluruh masyarakatPendidikan atau edukasi kesehatan adalah upaya atau cara pendidik untuk mempengaruhi orang lain baik secara individu maupun kelompok masyarakat agar dapat melaksanakan perilaku hidup sehat, sedangkan secara operasionalnya edukasi kesehatan adalah suatu kegiatan dalam memberikan serta meningkatkan baik pengetahuan maupun sikap seseorang dalam menjaga juga meningkatkan kesehatannya. Menurut Undang-Undang Kesehatan No. 23 Tahun 1992 dan juga WHO menyatakan bahwa kemampuan dan juga peran serta masyarakat dalam meningkatkan dan

produktif baik secara ekonomi maupun secara sosial. Penkes terdapat pada semua program kesehatan (Promkes) baik dalam 
pemberantasan penyakit menular, sanitasi lingkungan, gizi masyarakat, pelayanan

tujuan dari pendidikan atau edukasi kesehatan adalah meningkatkan

Menurut Notoatmodjo (2007) mengatakan bahwa faktor-faktor yang dapat mempengaruhi pengetahuan seseorang adalah usia, pendidikan, pengalaman serta informasi. Lama menderita penyakit $\mathrm{TB}$ bisa juga dipengaruhi oleh pengetahuan yang kurang dalam hal pengobatan dan juga sikap masyarakat atau keluarga dalam memotivasi pasien, memperhatikan pengobatannya dan juga makanan serta pencegahannya selain dari itu peran keluarga sangat penting dalam pengobatan TB Paru dari dukungannya serta perawatannya, kedekatan penderita dengan anggota keluarga sangat mempengaruhi, sebab apabila seseorang dekat dan nyaman dengan salah satu anggota keluarga maka penderita akan patuh dan mau mendengarkan apa yang dikatakannya, seperti kedekatan suami dan istri, anak dan orang tua, mereka akan paham kebutuhan apa yang diperlukan salah satu dari anggotanya..

Menurut Ahmad et al (2020) menyatakan bahwa terjadi peningkatan nilai pengetahuan setelah diberi penyuluhan kesehatan tentang pengobatan rutin pasien TB Paru. Menurut penelitian Suryanta et al (2016) ada peningkatan skor pengetahuan pada kelompok yang diberi intervensi promosi kesehatan sedangkan pada kelompok kontrol tidak ada peningkatan skor pengetahuan. Jadi dalam hal ini edukasi menggunakan media booklet berbahasa Tetun sangat efektif untuk dijadikan media edukasi kesehatan di Timor Leste tentang pencegahan TB Paru, karena menggunakan bahasa lokal dan kalimatnya lebih mudah untuk nilai pengetahuan dan sikap caregiver dalam mencegah penularan TB pada anggota keluarga melalui pendidikan kesehatan media audiovisual dan media booklet. Jadi kesimpulannya bahwa edukasi kesehatan menggunakan media booklet sangat mempengaruhi pengetahuan dan sikap seseorang dalam menjaga kesehatan keluarga maupun dirinya sendiri. menjadi seluruhnya berpengetahuan baik dan juga sikap keluarga ada peningkatan nilai pada tingkatan sikap cukup. kesehatan dan juga program-program

dipahami oleh keluarga maupun pasien dan juga booklet ini bisa dibawa pulang sehingga dapat dipelajari dirumah, dengan ini kita dapat meningkatkan pengetahuan penderita maupun keluarga serta dapat merubah sikap mereka dalam pencegahan penularan TB. Penelitian ini diperkuat oleh penelitian Maghfiroh, et al (2017). menunjukkan bahwa terjadi peningkatan pengetahuan responden antara sebelum dan sesudah mendapatkan edukasi. Walaupun penelitian ini sama-sama menggunakan bahasa daerah, yang membedakan penelitian ini penggunaan bahasa sesuai dengan yang digunakan pada daerah setempat seperti bahasa Tetun yang digunakan didaerah Dili, karena bahasa ini sering digunakan sehingga dapat mempermudah pemahaman penderita maupun keluarga dalam pencegahan TB Paru. Penelitian.

Sikap dalam penelitian ini tidak ada perubahan yang signifikan, tapi ada peningkatan nilai pada sikap keluarga pre dan post test dalam pemberian booklet berbahasa Tetun, karena sikap seseorang tidak bisa dinilai pada waktu yang singkat dan juga sikap tidak bisa dinilai oleh individu itu sendiri, sebab sikap kalau dinilai secara pribadi individu itu sendiri maka individu tersebut merasa sikapnya sudah benar. Jadi sikap perlu adanya observasi atau pengamatan secara langsung oleh orang lain dalam hal ini adalah peneliti, agar dalam menilai sikap bisa lebih maksimal, dengan jangka waktu yang panjang karena sikap ada yang bisa bersifat sementara dan juga jangka panjang. Penelitian sikap menggunakan booklet berbahasa Tetun diperkuat oleh penelitian Menurut penelitian Hartiningsih et al (2019) menyatakan ada peningkatan

\section{KESIMPULAN DAN SARAN Kesimpulan}

Edukasi TB melalui media booklet berbahasa Tetun efektif dalam meningkatkan pengetahuan serta perubahan sikap keluarga dalam

\section{Saran \\ Bagi Puskesmas: Penelitian ini dapat menginformasikan kepada petugas kesehatan bahwa memberikan edukasi}


kesehatan menggunakan media booklet berbahasa Tetun sebagai alat alternatif untuk meningkatkan pengetahuan dalam pencegahan penularan TB Paru bagi keluarga maupun masyarakat. Bagi Masyarakat: Informasi dalam booklet ini menggunakan bahasa lokal yaitu bahasa Tetun, diharapkan bisa menambah pengetahuan dan juga dapat merubah sikap keluarga ataupun masyarakat dalam pencegahan penularan TB Paru.

Bagi Peneliti Selanjutnya: Media booklet sangat efektif dalam pendidikan kesehatan kepada keluarga dan masyarakat, sehingga peneliti berharap peneliti selanjutnya dapat memodifikasi lagi media booklet ini menjadi lebih menarik dan juga pengukuran sikap bisa dioptimalkan lagi dengan cara observasi secara langsung. Bagi Institusi / Pendidikan: Media booklet ini bisa digunakan sebagai bahan ajar untuk mahasiswa serta dapat mengajarkan mahasiswa dalam pembuatan booklet dengan mempertimbangkan kondisi setempat seperti dalam penggunaan bahasa dan gambar sesuai dengan daerah setempat, agar dapat digunakan sebagai alat alternatif dalam memberikan edukasi kesehatan kepada keluarga/masyarakat tentang pencegahan penularan TB Paru.

\section{DAFTAR PUSTAKA}

Ahmad Yani, Tasya,Syam. 2020. Edukasi kesehatan untuk meningkatkan pengetahuan tentang pengobatan rutin pasien $\mathrm{TB}$ paru. https//jurnal.unismuhpalu.ac.id/ind ex.php/MPPKI/article/view/1032

Aisah, Sahar \& Hastono. 2010. Pengaruh Edukasi Kelompok Sebaya TerhadapPerubahan Perilaku Pencegahan Anemia Gizi Besi Pada anita Usia

Maghfiroh, Pratama \& Rachmawati. 2017. Pengaruh Pemberian Edukasi Menggunakan Buku Saku Bergambar dan Berbahasa Madura Terhadap Tingkat Pengetahuan Penderita Dan Pengawas Menelan Obat Tubercolosis Paru.

https://doi.org/10.19184/pk.v5i3.58 92

Murti,Prabandari\& Riyanto 2006.Efektivitas Promosi Kesehatan Dengan Peer Education Pada Kelompok Dasawisma Dalam Upaya Penemuan TersangkaPenderitaTBParu.https://jo urnal.ugm.ac.id/bkm/article/view/36 49.
Subur.https://jurnal.unimus.ac.id/in dex.php/psn12012010/article/view/ 56.

Asiah, Suyanto \& Munir. 2014. Gambaran Perilaku Pasien TB Paru Terhadap Upaya Pencegahan Penyebaran PenyakitTBParu.https://jom.unri.ac.i d/index.php/JOMFDOK/article/view/ 2946

Djannah, Suryani \& Purwati (2009) tentang Hubungan Tingkat Pengetahuan Dan Sikap Dengan Perilaku Pencegahan PenularanTBC.http://journal.uad.ac.i d/index.php/KesMas/article/view/11 09

Fahruddin.Karim,D\&Wahyuni,S.2019.Gamb aran pelaksanaan fungsi perawatan keluarga pada anggota keluarga yang menderitaTBParu.https://jom.unri.ac id.

Febriansyah,R. 2017. Hubungan tingkat pengetahuan keluarga dengan upaya pencegahan penularan TB Paru pada keluarga.https://ums.ac.id.

Hartingsih \& Hikmawati.2019.pengaruh pendidikan kesehatan terhadap sikap caregiver dalam mencegah penularan tuberculosis pada anggota

keluarga.DOI:https//doi.org/10.325 04/sm.v13i2.100.

Hidayat Aziz. 2007. Metode Penelitian Keperawatan Dan Teknik Analisa Data. Edisi I. Salemba Medika. Jakarta.

Jhonson \& Leny. 2010. Keperawatan Keluarga. Cetakan I. Jakarta.

Kusuma Kelana Dharma. 2011. Metodologi Penelitian Keperawatan ( pedoman melaksanakan dan menerapkan hasil penelitian). TIM (Trans Info Media). Jakarta.

Nurhayati, Kurniawan \& Mardiah. 2015. Perilaku Pencegahan Penularan Dan Faktor-Faktor Yang Melatarbelakanginya pada pasien Tubercolosis Multidrugs Resisten (TBMDR)http://jkp.fkep.unpad.ac.id/ index.php/jkp/article/viewFile/118/ 109

Notoatmodjo. S, 2011. Metode Penelitian Kesehatan. Jakarta: Rineka Cipta.

Nursalam. 2011. Konsep Dan Penerapan Metodologi Penelitian Ilmu keperawatan. Edisi 2. Jakarta : Salemba Medika 
2014. Metodologi Penelitian Ilmu Keperawatan. Edisi 3. Salemba Medika. Jakarta.

Nursalam. 2011. Konsep dan Penerapan Metodologi Penelitian Ilmu Keperawatan. Pedoman Skripsi, Tesis, dan Instrumen Penelitian Keperawatan.Jakarta: Salemba Medika.

Pameswati,P,Halim,A\&Yustika,L.2016.Tingk at kepatuhan penggunaan obat pada pasienTuberkulosis.DO10.29208/jsf k.2016.2.2.60

Purwanto. Hubungan Antara Sikap Dengan Perilaku Keluarga Tentang Pencegahan Penyakit Menular Tuberkulosis. Jurnal Keperawatan \& Kebidanan-Stikes Dian HusadaMojokerto.https://jurnalonlin e.lppmdianhusada.ac.id/index.php/j $\mathrm{kk} /$ article/viewFile/61/0

Purba,D. 2015. Hubungan Pengetahuan Penderita Tuberkulosis Paru Dengan Tindakan Pencegahan Penularan TB.file:///C:/Users/HP/Downloads/4 8-48-1-PB\%20(1).pdf.

Putri, Sofiatin \& Roesli. 2017. Gambaran Penangkapan Edukasi Yang Diberikan Kepada Pasien Hipertensi.http://jurnal.unpad.ac.id /jsk_ikm/article/view/11962

Salsabila, Utami \& Nugraheni. 2018. Efektivitas Edukasi Kesehatan (Ceramah Dan SMS Gateway) Terhadap Pengetahuan Deteksi Dini Kehamilan Resiko Tinggi Pada Ibu Hamil,Jurnal Kedokteran

Diponegoro.https://ejournal3.undip. ac.id/index.php/medico/article/view /20704.

Septia,A.2014.Hubungan dukungan keluarga dengan kepatuhan minum obat pada penderita TB.https://jom.unri.ac.id.

Solon, Putri \& Naing. 2017. Pengaruh Edukasi Dengan Pendekatan Teori Model Behavioral System Dorothy E.

dikankesehatandengan\%20jurnal\%20eduka si.pdf

Tode,R,S.,Kurniasari,M,D.,Fretes,D,F.,\&Sanu bari,T,P,E.2019.Gambaran resiko penularan terhadap keluarga dengan pasien TB paru di Salatiga.DOI: 10.35842/formil.v4i1.229

Wulandari. 2017. Pengaruh Aplikasi Telehomecare Terhadap
Johnson Terhadap Penurunan ekanan Darah Pada Pasien Hipertensi

Suryanta,N.,Notoatmodjo,S.,\&Silaban,G.201

6. The Influence of health promotion on behavior in preventive and treatment of pulmonary tuberculosis on prisoner grade I Of medan city. www.eajournals.org.

Sulistyo Andarmoyo. 2015. Pemberian Pendidikan Kesehatan Melalui Media Leaflet Efektif Dalam Peningkatan Pengetahuan Perilaku Pencegahan Tuberkulosis Paru Di KabupatenPonorogo.https://anzdoc. com/pemberian-pendidikan-

kesehatan-melalui-media-leafletefektif.html.

Sumartini,N.P. 2014. Penguatan Peran Kader Kesehatan Dalam Penemuan Kasus Tuberkulosis (TB) BTA Positif Melalui Edukasi Dengan Pendekatan Theory Of Planned Behavior (TPB).Jurnal Kesehatan Prima.https://anzdoc.com/penguata n-peran-kader-kesehatan-dalampenemuan-kasustuberku.html.

Suprayitno, E., Khoiriyati, A., \& Hidayati, T. (2017). Gambaran Efikasi Diri dan Peak Expiratory Flow Rate Pasien Penyakit Paru Obstruktif Kronis (PPOK). Media Ilmu Kesehatan, 6(1), 38-45.

Syahrini,L.E.2013.Pengetahuan dan sikap pengawas minum obat Tuberkulosis Paru sebelum dan sesudah diberikan media buku saku. http://dx.doi.org/10.20527/dk.vlil. 1653.

Syarif,M.B et al. 2015. Efektifitas Pendidikan Kesehatan Dengan $\mathrm{Au}-$ dio Visual Terhadap Pengetahuan Dan Perilaku Hidup Sehat Keluarga Tentang Pencegahan Penularan Tuberkulosis Paru. file:///F:/184291IDefektifitaspendi Pengetahuan Penderita Tuberculosis Paru Tentang Penularan Penyakit Tuberculosis Jurnal Ners dan Kebidanan,Volume4,https://media.n eliti.com/media/publications/23267 5-the-effect-of-telehomecareapplication-t-ef638dc5.pdf 